\title{
Mushroom Diagnosis Assistance System Based on Machine Learning by Using Mobile Devices
}

\author{
Intisar Shadeed Al-Mejibli \\ University of \\ Information Technology and Communications \\ IRAQ \\ dr.intisar.almejibli@gmail.com
}

\author{
Dhafar Hamed Abd \\ Al-Maaref University Collegı \\ IRAQ
}

dhafar.dhafar@gmail.com

Recived : $1419 \backslash 2017$

Revised : $8 \backslash 10 \backslash 2017$

Accepted : 11\10\2017

\begin{abstract}
Picking the wild mushrooms from the wild and forests for food purpose or for fun has become a public issue within the last years because many types of mushrooms are poisonous. Proper determination of mushrooms is one of the key safety issues in picking activities of it, which is widely spread, in countries. This contribution proposes a novel approach to support determination of the mushrooms through using a proposed system with mobile devices. Part of the proposed system is a mobile application that easily used by a user - mushroom picker. Hence, the mushroom type determination process can be performed at any location based on specific attributes of it. The mushroom type determination application runs on Android devices that are widely spread and inexpensive enough to enable wide exploitation by users.

This paper developed Mushroom Diagnosis Assistance System (MDAS) that can be used on a mobile phone. Two classifiers are used which are Naive Bays and Decision Tree to classify the mushroom types. The proposed approach selects the most effective of the already known mushroom attributes, and then specify the mushroom type. The use of specific features in mushroom determination process achieved very accurate results.
\end{abstract}

Keywords: Android, Decision Tree, Mushroom Determination, Mobile Device, Naive Bays.

\section{Introduction}

Mushrooms are one of the fungi types and currently gain super food status because they have some of the most potent nutrients on the plant. Generally, mushrooms have significant advantages such as destroying cancer cells, eradicating viruses, boosting human immune system, managing weight, improving nutrition and promoting better diet quality, and etc [1][2]. In addition to, their environmental benefits such as cleaning polluted soil and being a potential source of fuel. Hence, generally, mushroom consumption has been increased in many countries, and specifically, the consumption of edible wild mushrooms has become more popular among people [3].
Wild edible mushroom are consumed because they are source of nutrition and they are occasionally source of medicine. The people, who are practicing folk medicine, are consumed mushroom which known as medicinal mushrooms [4]. From the other hand, psychedelic mushrooms are sometimes consumed for purposes of recreational or entheogenic and not commonly used as food, because they have strong psychological effects [3]. Therefore, the value of wild edible fungi is of similar value with many vegetables and in some cases have a higher food value. Thus, the nutritional value of wild edible fungi should not be underestimated [3] [5] [6]. 
In spite of mushroom various benefits, must take into consideration that not all of them are edible because out of 10,000 species of mushrooms, 50 to 100 types are toxic [1] known as inedible. The inherent risks of eating the wild inedible mushrooms are variety and great, with effects ranging from simple symptoms such as a mild stomachache and simple indigestion to life threatening conditions and death in some cases. In the field of botany, no general rule exists for the identification of these dangerous and even lifethreatening fungi. There are many wild edible mushrooms such as champignon and others are inedible like death cap which is the most dangerous type as it causes death in more than 50 percent of the incidents [7].

Currently, mushroom determination process is performed by robot and automated sorting machine in food industry. In these cases, the used technique is developed for a specific task and it cannot be used in more general applications. This attributed to constrain these simple techniques to limited features such as color, making them not proper for general applications [8].

The recent updates in communication, mobile devices and technology facilitate developing a mushroom determination system using specific characteristics selected from mushrooms features. In fact, combining a mobile phone with the mushroom determination system has many advantages. For example, mobile phones are of daily use and easy to be understood by anyone. Further, they are powerful and quickest means of using technology. Moreover, with the internet enabled mobile phone, it becomes easily benefit of an internet server. As a result with phone, internet and a determination system, any person could easily know whether a mushroom is edible or inedible [9].

Such system based on analyzing and investigating the mushroom features in order to classify the mushroom depending on their well known features (such as color histogram, hog, and odor). The main goal of this research is to design and implement Mushroom Diagnosis Assistance System (MDAS) which is offers an application running on a mobile Android device. This application provides the user with ability of identifying some mushroom attributes directly in the nature. The analyzing is done on basis of the user interaction with designed and implemented mobile application. Then the mushroom is determined and the results are presented as a final decision which is the mushroom edible or not. In addition the proposal offers many other services like providing the used with information about the all known types of mushrooms.
The rest of this paper is organized as follows: Background is described in section 2. Section3 presents research objectives. Dataset description details in section 4. Section 5 explains proposed system. Analyzing results detail in section 6 . Section 7 includes the conclusion.

\section{Background}

This section presents some principles to facilitate reading the other sections of this research. It describes the classification concept, Naive Bayes and Decision tree.

\subsection{Classification}

Classification process is predicting categorical class labels which are discrete or unordered. Training set and the values (class labels) are used in constructing a model to classify the attribute and then use it in classifying new data.

The task of data classification includes two-step process. The first process is learning step representing by constructing the classification model. The second process is a classification (testing) step and in this step represents the constructed model which is used given data to predict class labels for them.

The researchers have been proposed several classification methods in machine learning, pattern determination, and statistics. For example the techniques that can be used for classification are Naive Bays, and decision tree [10].

\subsection{Naive Bayes}

The Naive Bayes algorithm is known with its simplicity. It is regarded as a probabilistic classifier which counts the frequency and combinations of values in a given data set to compute a set of probabilities. The algorithm based on Bayes theorem and assumes the class variable value results from the independence of all attributes [11] [12].

The Naïve Bayesian algorithm offers an adaptable method for dealing with whatever number of features or classes on probability theory, and it frequently used with supervised learning. It has the ability to that examines all its training input and it is known as the asymptotically fastest learning algorithm. Although, the model nature is characterized with simplicity, this algorithm demonstrates efficient performance in a very wide variety of problems. Further, small amounts of improper data, or "noise," do not affect the results by much [13].

Many studies have founded that the performance of simple Bayesian classifier is comparable to the performance of decision tree and selected neural network classifiers [10][14]. 


\subsection{Decision tree}

Decision tree is one of the common methods which are used for inductive inference. The induction of decision tree is the decision trees learning from training tuples of class-labeled. The structure of decision tree is like tree, where test on an attribute is represented by internal node (non leaf node), outcome of the test is denoted by branch, and class label is held by leaf node (or terminal node). The root node is the topmost node in a tree. [10][15]

The algorithm consists of the following process: it used all tuples in the training set, selects the most attribute that produces maximum information for classification, and for this attribute a test node is generated. Then, top down induction is performed in which the current set of tuples is divided by decision trees based on their values of the current test attribute. The process of classifier generation stops, if one of the following conditions is met: first all tuples in a subset related to the same class, or it would not be useful to precede with further separation into other subset. The algorithm of decision tree usually uses "information gain" measures which is an entropy-based measure. This measurement is used as a heuristic for selecting the features that will best split the training data into independent classes. [10][13].

\section{Research Objectives}

The main goal of this research is determining if mushrooms are poisonous or edible. This could be achieved by designing and implementing a Mushroom Diagnosis Assistance System (MDAS) that is able to analyze the input data and conclude precise decision that lead to mushroom diagnosis. Additionally, this research aims to reduce the gap of knowledge between different individuals in mushroom diagnosis. The following details the specific objectives of this research:

- Identify the target and the effective attributes (variables).

- Preprocess mushroom data so that it is suitable for training.

- Design and implement an application running on a mobile device that is performing the mushroom determination task.

- Maintain an updated database in an authorized institute that includes known species of mushrooms and newly discovered ones which are recently recorded.

- Use the system after testing and validating its performance.

\section{Dataset Description}

The used datasets is obtained from UCI (Unique Client Identifier) Repository of Machine Learning Database [16]. The dataset has includes description of the hypothetical sample which is corresponding to the 23 species of the gilled mushroom in the Lepiota and Agarics Family. Each one of those species is identified as the definitely edible, definitely poisonous, unknown edibility, or is not recommended at all. The latter class has been combined with a poisonous and edible based on 22 physical attributes as recorded in [17].

\section{Data distribution:}

The dataset was distributed into two different classes:

- Class 1 = Edible with the number of 4208 instances $(51.28 \%)$

- Class 2 = Poison with the number of 3916 instances $(48.2 \%)$

There are total of 8124 instances that were captured.

\section{Setting a Target}

the main target of this experiment is determining if mushroom is edible $(\mathrm{Y})$ or poisonous $(\mathrm{N})$

\section{Normalizing Attributes}

before any data train, the data normalization process is required. This to ensure all data value must be in string so it can be train.

The data from the UCI repository came encoded as a txt file with 22 feature values encoded as single ASCII characters and a label of either "Y" for edible or "N" for poisonous on each line of the file. Full explanations of the encodings are available at the repository at [17]. The whole data file contains 8,124 instances of mushrooms. Roughly half are classified as poisonous and half as edible. Mushrooms that were classified as poisonous do include some of unknown toxicity and have been classified as poisonous on the side of caution. [17] .

\subsection{Mushroom Attributes}

The mushroom 22 attributes in the dataset are represented in table 1 . These attributes represent the well known mushroom attributes. Hence, a string of size 22 bytes ( 22 characters) is required to describe each mushroom. All the mushroom description strings are of the same size because each attribute has only one possibility [17].

There are 8124 instances in data set. These instances are distributed as 4208 edible mushrooms and 3916 poisonous mushrooms. Stalk-root attribute, which is numbered 11 , misses 2480 attributes. The sign '?' is used to note the 
missing attributes in dataset and same sign is used in string describing of the mushroom when the attribute is missing [17]. A binary vector $(0-1)$ can be used to describe the mushroom instead of using string because the data of mushroom is nominal.

Table 1. Attributes of Mushroom Description in the Dataset

\begin{tabular}{|c|c|c|}
\hline Attribute no. & Attribute name & Possibilities \\
\hline 1 & cap-shape & bell (b), conical (c), convex (x), flat (f), knobbed (k), sunken (s) \\
\hline 2 & cap-surface & fibrous (f), grooves (g), scaly (y), smooth (s) \\
\hline 3 & cap-color & $\begin{array}{l}\text { brown (n), buff (b), cinnamon (c), gray (g), green (r), pink (p), } \\
\text { purple (u), red(e), white (w), yellow (y) }\end{array}$ \\
\hline 4 & bruises ? & bruises (t), no (f) \\
\hline 5 & odor & $\begin{array}{l}\text { almond (a), anise (1), creosote (c), fishy (y), foul (f), musty (m), } \\
\text { none (n), pungent (p), spicy (s) }\end{array}$ \\
\hline 6 & gill-attachment & attached (a), descending (d), free (f), notched (n) \\
\hline 7 & gill-spacing & close (c), crowded (w), distant (d) \\
\hline 8 & gill-size & broad (b), narrow (n) \\
\hline 9 & gill-color & $\begin{array}{l}\text { black (k), brown (n), buff (b), chocolate (h), gray (g), green(r), } \\
\text { orange (o), pink (p), purple (u), red (e), white (w), yellow (y) }\end{array}$ \\
\hline 10 & stalk-shape & enlarging $(\mathrm{e})$, tapering $(\mathrm{t})$ \\
\hline 11 & stalk-root & $\begin{array}{l}\text { bulbous (b), club (c), cup (u), equal (e), rhizomorphs (z), rooted } \\
\text { (r), missing (?) }\end{array}$ \\
\hline 12 & $\begin{array}{l}\text { stalk-surface } \\
\text { above-ring }\end{array}$ & ibrous (f), scaly (y), silky (k), smooth (s) \\
\hline 13 & $\begin{array}{l}\text { stalk-surface } \\
\text { below-ring }\end{array}$ & ibrous (f), scaly (y), silky (k), smooth (s) \\
\hline 14 & $\begin{array}{l}\text { stalk-color } \\
\text { above-ring }\end{array}$ & $\begin{array}{l}\text { brown }(n) \text {, buff }(b) \text {, cinnamon }(c) \text {, gray }(g) \text {, orange }(o) \text {, pink }(p) \text {, } \\
\text { red }(e) \text {, white }(w) \text {, yellow }(y)\end{array}$ \\
\hline 15 & $\begin{array}{l}\text { stalk-color } \\
\text { below-ring }\end{array}$ & $\begin{array}{l}\text { brown }(\mathrm{n}) \text {, buff }(\mathrm{b}) \text {, cinnamon }(\mathrm{c}) \text {, gray }(\mathrm{g}) \text {, orange }(\mathrm{o}) \text {, pink }(\mathrm{p}) \text {, } \\
\text { red }(\mathrm{e}) \text {, white }(\mathrm{w}) \text {, yellow }(\mathrm{y})\end{array}$ \\
\hline 16 & veil-type & partial (p), universal (u) \\
\hline 17 & veil-color & brown (n), orange (o), white (w), yellow (y) \\
\hline 18 & ring-number & none $(\mathrm{n})$, one $(\mathrm{o})$, two $(\mathrm{t})$ \\
\hline 19 & ring-type & $\begin{array}{l}\text { cobwebby }(c) \text {, evanescent }(e) \text {, flaring }(f) \text {, large }(1) \text {, none }(n) \text {, } \\
\text { pendant }(p) \text {, sheathing }(s) \text {, zone }(z)\end{array}$ \\
\hline 20 & $\begin{array}{l}\text { spore-print- } \\
\text { color }\end{array}$ & $\begin{array}{l}\text { black }(k) \text {, brown }(n) \text {, buff }(b) \text {, chocolate }(h) \text {, green }(r) \text {, orange (o), } \\
\text { purple (u), white (w), yellow (y) }\end{array}$ \\
\hline 21 & population & $\begin{array}{l}\text { abundant (a), clustered (c), mumerous (n), scattered (s), several } \\
\text { (v), solitary (y) }\end{array}$ \\
\hline 22 & habitat & $\begin{array}{l}\text { grasses }(\mathrm{g}) \text {, leaves }(1) \text {, meadows }(\mathrm{m}) \text {, paths }(\mathrm{p}) \text {, urban }(\mathrm{u}) \text {, waste } \\
(\mathrm{w}) \text {, woods }(\mathrm{d})\end{array}$ \\
\hline
\end{tabular}


When attribute includes value 1 is used and 0 used when the attribute does not include values. The attributes have a definite length because there are only certain possibilities for describing the attribute, i.e. for attribute 21 , population, there are six options, abundant (a), clustered (c), numerous (n), scattered (s), several (v), solitary (y). The feature scattered (s) can be representing as the binary string 000100 [17]. The proposed system based on these attributes in taking the decision for example:

Mushroom is most likely poisonous if: Spore print color is green

While

Mushroom is most likely edible if: Odor is almond, anise, or no smell at all

\section{Proposed System}

Proposed system consists of unified database, web application (server) and mobile phone application (client). Figure 1, represents the three components of proposed system. Unified database is maintained by an authorized institute such as hospital or college of Agriculture and it keeps updated information about all the known and newly discovered mushroom spices to a unified accessible database. Web application and Mobile phone application have common services, which are Mushroom Determination, Adding New Mushroom Spices, and Exploring Mushroom Spices. Although these two applications have a common services, these services are different in sort of their performance because the web application is designed for specialists and Mobile application is designed for users who are interested in Mushroom picking. The web application has more privileges in accessing and modifying the unified database.

In addition, web application offers some services for specialists only such as reply to user question and check the new discovered mushroom data before adding it to unified database.

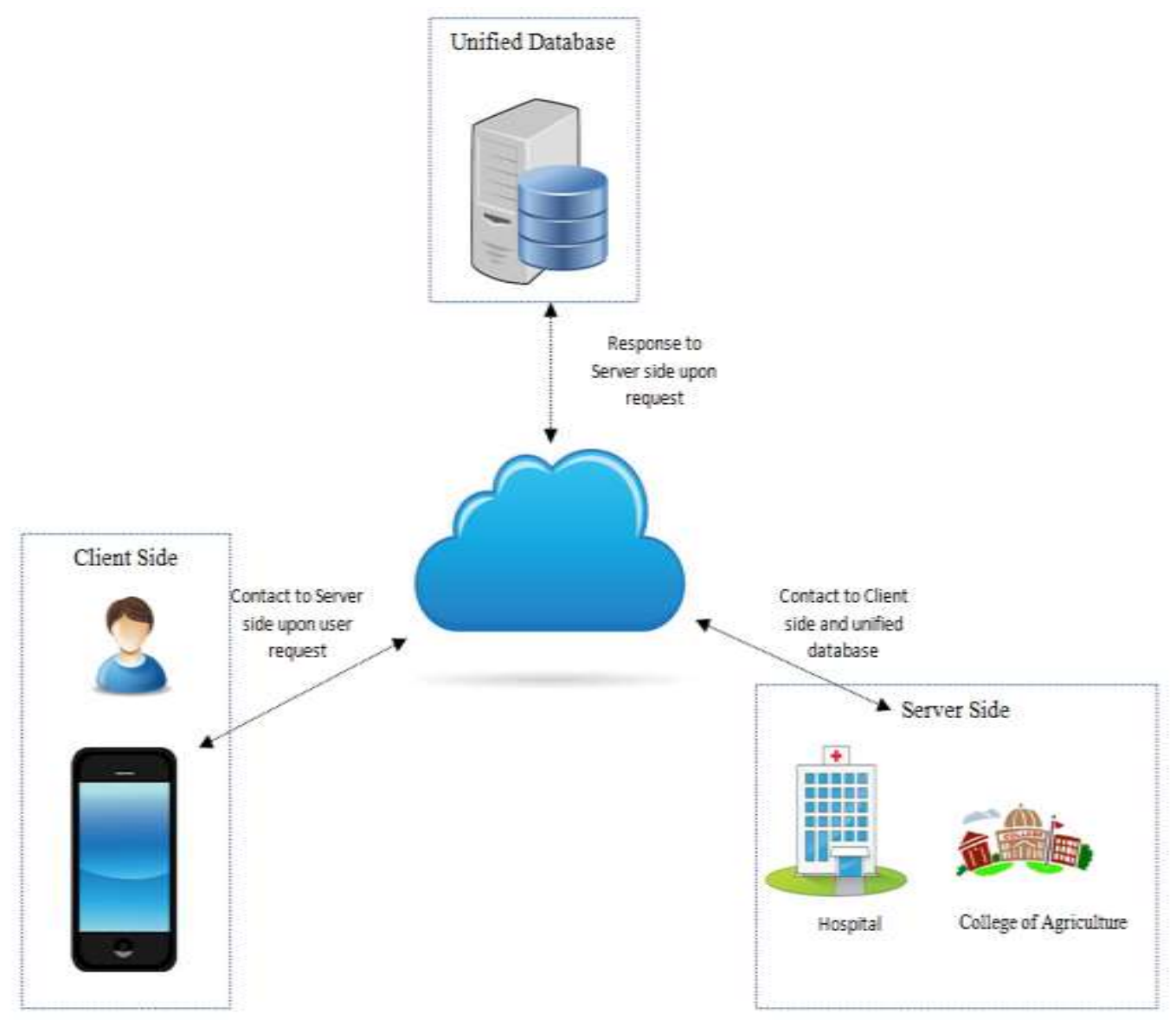


1- Mushroom Determination service by which the user may easily know the type of suspicious mushrooms (edible or not) based on providing the application with some of mushroom attributes. If the suspicious mushroom is unknown the mobile application offers the user to send request to server side including mushroom attributes such as image which is sent after compression.

2- Adding New Mushroom Spices service, this service allow user to add a newly discovered mushroom spices to a unified database. This service requests the user to specify some of the discovered mushroom features like (color, description, image (sent after compression), and location) to send them to unified database. The newly discovered mushroom will be added to the unified database after the authorization of specialist.

3- Exploring Mushroom Spices service: this service allows the user to explore information about mushrooms, their features, images, and etc.

Further, the mobile phone application offers more services such as Remote Mushroom Determination. This services facilitates connect the user with an authorized expert from a local institution such as hospital or agricultural college, in order to provide the user with assistance in some critical situation. For example when Mushroom Determination service fails in its task or when emergency situations occurred Mushroom determination process includes two phases training phase and testing phase. Figure 2 shows the methodology of the proposal in training phase. Training phase uses two classifiers (Nave Bayse and Decision Tree) for comparison purposes. Test phase base on Decision Tree.

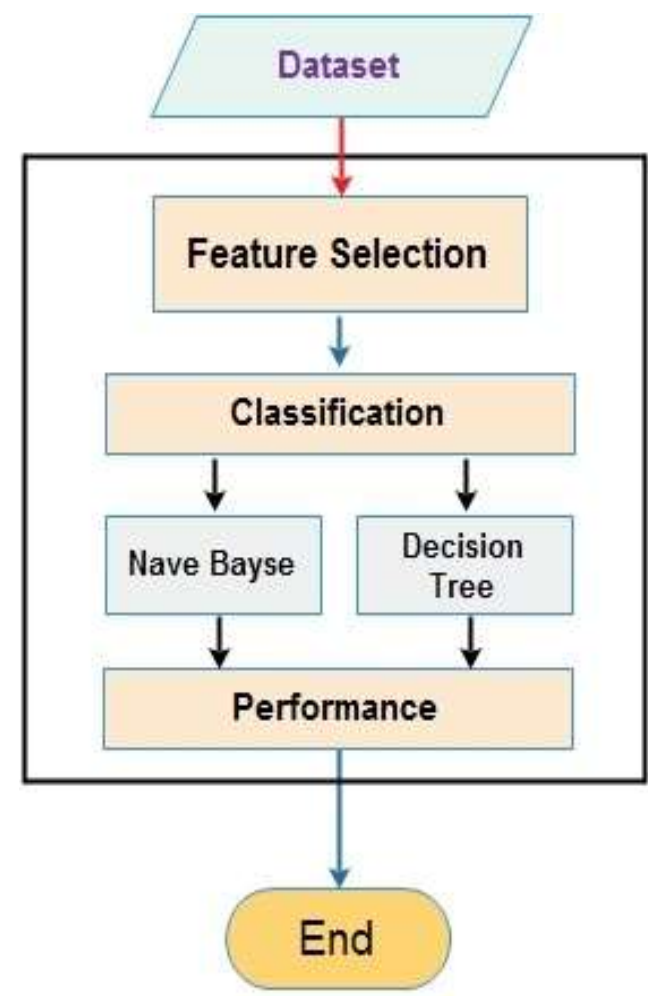

Figure 2. The Methodology of the Proposal in Training Phase

\subsection{Mushroom Determination}

Five of the features described in previous section are used to specify the mushroom class (edible or not) after applying many experiments on the available dataset the proposal find out that the features shown in table 2 are enough to know the mushroom class. These five features are odor, spore-print-color, habitat, gill-size and cap-color.

\subsection{Features suggested by fast decision tree algorithm}

Five features are the most effective features in final decision. Figure 3, shows the steps of mushroom determination process based on the most dominant features [16]. 


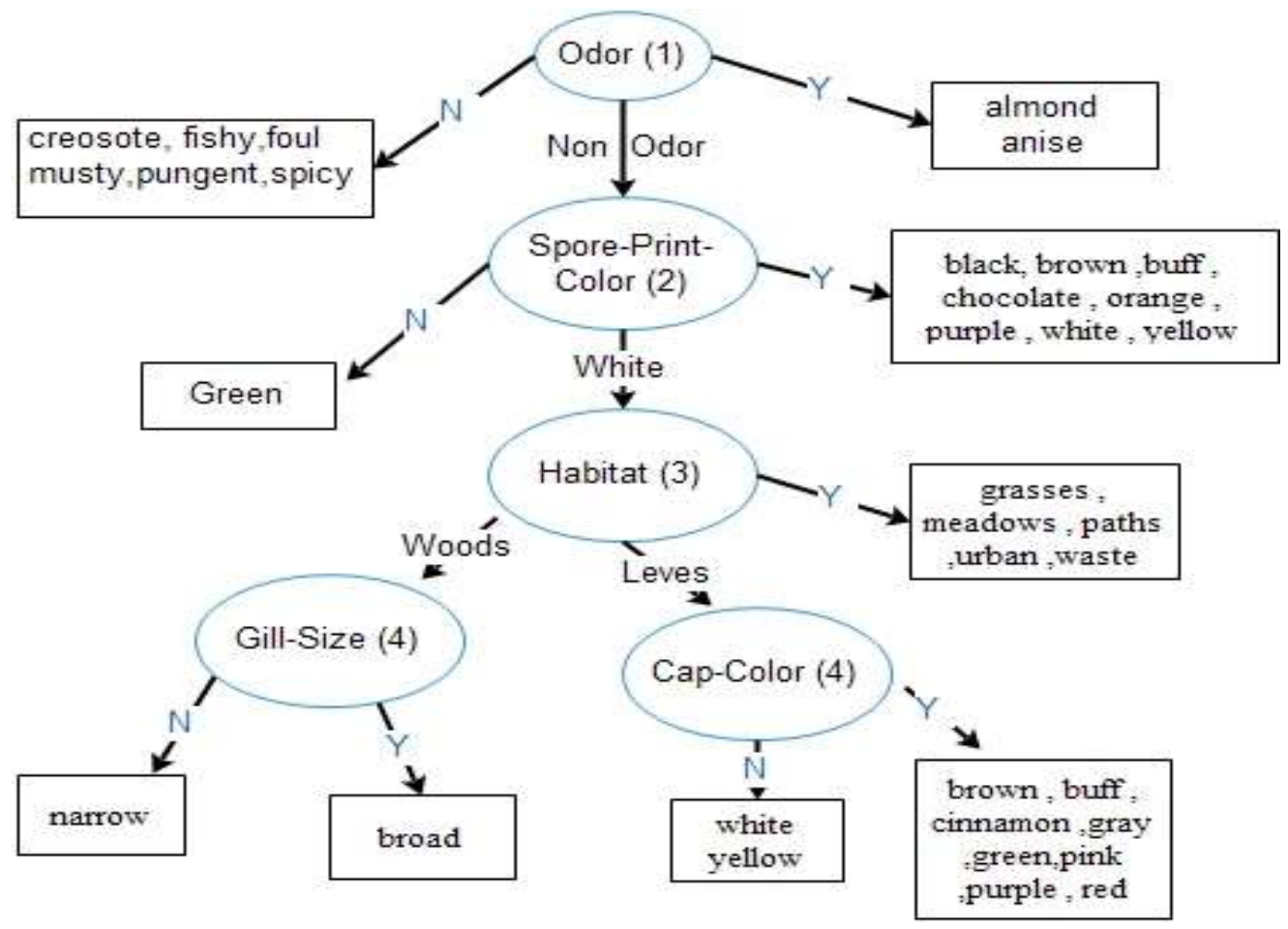

Figure 3. Classification Process of Mushroom Determination

Table 2. The Most Dominant Attributes of Mushroom

\begin{tabular}{|l|l|l|}
\hline Attribute no. & Attribute name & \multicolumn{1}{|c|}{ Possibilities } \\
\hline 1 & odor & $\begin{array}{l}\text { almond (a), anise (1), creosote (c), fishy (y), foul (f), musty (m), } \\
\text { none (n), pungent (p), spicy (s) }\end{array}$ \\
\hline 2 & $\begin{array}{l}\text { spore-print- } \\
\text { color }\end{array}$ & $\begin{array}{l}\text { black (k), brown (n), buff (b), chocolate (h), green (r), orange (o), } \\
\text { purple (u), white (w), yellow (y) }\end{array}$ \\
\hline 3 & habitat & $\begin{array}{l}\text { grasses (g), leaves (1), meadows (m), paths (p), urban (u), waste } \\
(\mathrm{w}), \text { woods (d) }\end{array}$ \\
\hline 5 & gill-size & broad (b), narrow (n) \\
\hline 5 & cap-color & $\begin{array}{l}\text { brown (n), buff (b), cinnamon (c), gray (g), green (r), pink (p), } \\
\text { purple (u), red(e), white (w), yellow (y) }\end{array}$ \\
\hline
\end{tabular}


Intisar .S / Dhafar .H

\section{Analysis Results}

Two classifiers have been applied which are Naive Bays and Decision Tree in determination task. The two classifiers applied with features selection and without features selection. Table 3 shows the two classifiers performance without features selection regarding different parameters.

Table 4 presents the accuracy by class with features selection. Table 5 shows the two classifiers performance with features selection regarding different parameters. In general, the results show that the Decision Tree classifier achieved the best performance.

Table 3. Classifiers Performance without Features

\begin{tabular}{|c|c|c|}
\hline \multirow{2}{*}{ Parameters } & \multicolumn{2}{c|}{ Classifiers } \\
\cline { 2 - 3 } & Naive Bays & Decision Tree \\
\hline Time Second & 0.04 & 0.20 \\
\hline Correctly Classified Instances & $95.8272 \%$ & $99.9631 \%$ \\
\hline $\begin{array}{c}\text { Incorrectly Classified } \\
\text { Instances }\end{array}$ & $4.1728 \%$ & $0.0369 \%$ \\
\hline Kappa statistic & 0.9162 & 0.9993 \\
\hline Mean absolute error & 0.0419 & 0.0003 \\
\hline Root mean squared error & $0.175 \%$ & 0.0166 \\
\hline Relative absolute error & $8.3961 \%$ & $0.0671 \%$ \\
\hline Root relative squared error & $35.159 \%$ & $3.326 \%$ \\
\hline Total Number of Instances & 8124 & 8124 \\
\hline
\end{tabular}

Table 5. Classifiers Performance with Features Selection

\begin{tabular}{|c|c|c|}
\hline \multirow{2}{*}{ Parameters } & \multicolumn{2}{|c|}{ Classifiers } \\
\cline { 2 - 3 } Time Second & Naive Bays & Decision Tree \\
\hline Correctly Classified Instances & $98.4613 \%$ & 0.01 \\
\hline $\begin{array}{c}\text { Incorrectly Classified } \\
\text { Instances }\end{array}$ & $1.5387 \%$ & $0.0123 \%$ \\
\hline Kappa statistic & 0.9692 & 0.9998 \\
\hline Mean absolute error & 0.0197 & 0.0001 \\
\hline Root mean squared error & 0.101 & 0.0095 \\
\hline Relative absolute error & $3.9456 \%$ & $0.0293 \%$ \\
\hline Root relative squared error & $20.2095 \%$ & $1.8958 \%$ \\
\hline Total Number of Instances & 8124 & 8124 \\
\hline
\end{tabular}

Figure 4 and figure 5 show the average weights of classifications without feature selection and with feature selection.

The results show that using the features selection improves the performance of both classifiers in term of increase their accuracy and minimize the error. In addition to reduce the required time to get the final decision.

The same number of instances 8124 is used in two classifiers with and without features selection. With and without feature selection, the results show that the Decision Tree achieved the most correct classified instances and the least incorrect classified instances.

Table 4. Accuracy of Classifications

\begin{tabular}{|c|c|c|c|c|c|c|l|}
\hline \multirow{2}{*}{ Classifiers } & \multicolumn{9}{|c|}{ Accuracy By Class } \\
\cline { 2 - 9 } & $\begin{array}{c}\text { True } \\
\text { Positive }\end{array}$ & $\begin{array}{c}\text { False } \\
\text { Positive }\end{array}$ & Precision & Recall & F-Measure & $\begin{array}{c}\text { ROC } \\
\text { Area }\end{array}$ & Class \\
\hline Naive Bays & 0.984 & 0.014 & 0.984 & 0.984 & 0.984 & 0.999 & $\mathrm{~N}$ \\
\cline { 2 - 9 } & 0.986 & 0.016 & 0.985 & 0.986 & 0.985 & 0.999 & $\mathrm{Y}$ \\
\hline $\begin{array}{c}\text { Decision } \\
\text { Tree }\end{array}$ & 1 & 0 & 1 & 1 & 1 & 1 & $\mathrm{~N}$ \\
\cline { 2 - 9 } & 1 & 0 & 1 & 1 & 1 & 1 & $\mathrm{Y}$ \\
\hline
\end{tabular}




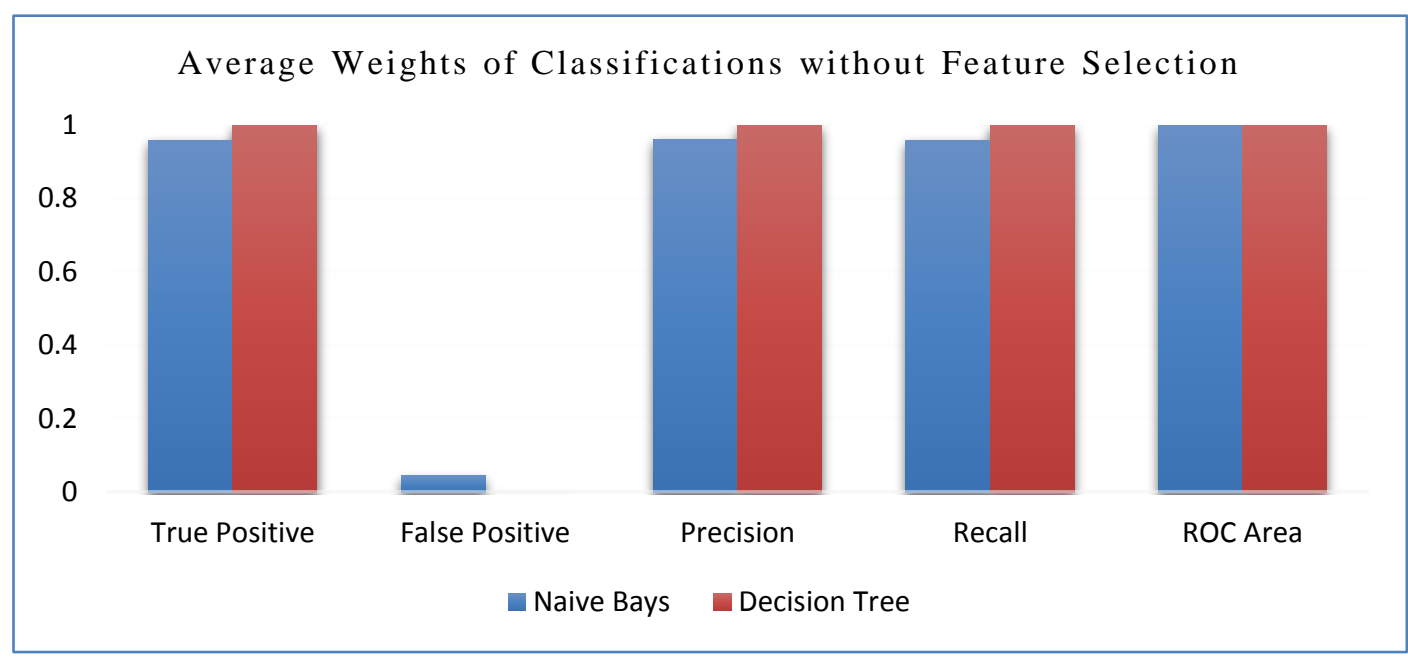

Figure 4. Average Weights of Classifications without Feature Selection

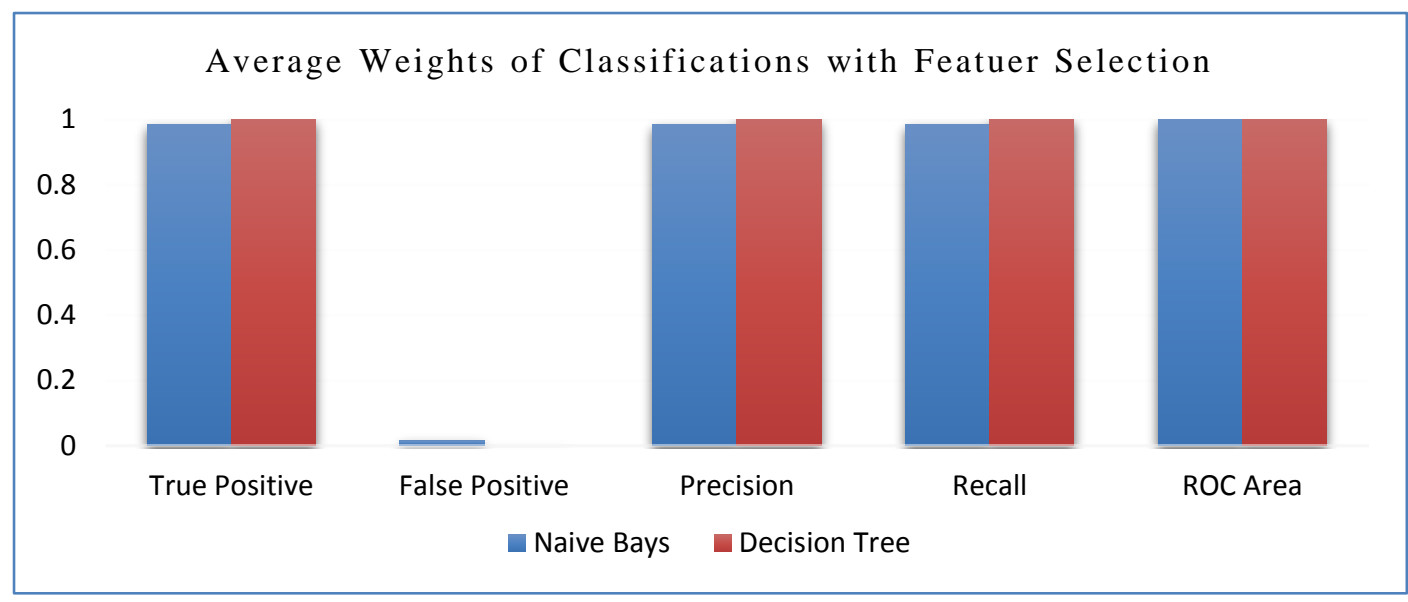

Figure 5. Average Weights of Classifications with Feature Selection

In addition to, all the calculated error measurements were the lowest with Decision Tree.

Hence, in spite that the Decision Tree spent more time in determination process, its performance was better than Naive Bays. However, the difference in time between the two classifiers is approximately less than $(0.01-0.0=0.01$ second $)$ with feature selection. Waiting 0.01 seconds represents very short time to get such critical decision.

\section{Conclusion}

Many species of mushrooms are poisonous making the task of picking the wild mushrooms from the wild and forests for food purpose or for fun too risky.
The symptoms of eating poisonous mushrooms can vary from slight gastrointestinal discomfort to death. Hence, who wants to pick a mushroom for food must be $100 \%$ sure of mushroom species before consumption

This paper developed Mushroom Diagnosis Assistance System (MDAS) consists of three components unified database, web application (server) and mobile phone application (client). MDAS maintains unified updated database about mushroom information under the supervision of the specialists and facilitates mushroom determination process on a mobile phone. This system offers a proper determination of mushrooms to achieve safety in picking mushroom, which is widely spread, in countries. 
This proposed determination approach includes two phases. First phase train the machine learning system and second phase used it in determination process. The suggested determination approach specifies the most effective features in determination process, and then finds the final decision. The use of specific features in mushroom determination process achieved very accurate results. Two classifiers are used which are Naive Bays and Decision Tree are applied for validation purpose. Both classifiers applied with and without feature selection. The results show that Decision Tree classifier achieved better results than Naive Bays in term of correctly classified instances, incorrectly classified instances and error measurements. While there is a slightly difference in the required time at the classification process, as the Naive Bays needs slightly less time than Decision Tree.

\section{References}

[1] Dr. Mercola, " Mushroom Nutrition: Discover Outstanding Fungal Benefits Infographic ", http://www.mercola.com/infographics/mushroo ms.htm.

[2] Lau Meng Fei, Rosnida Tajuddin, Masratul Hawa Mohd and Latiffah Zakaria, "Identification and factors affecting in-vitro growth of an indigenous mushroom, Boletus sp. from Bachok, Kelantan, Malaysia", tropical agricultural science journal, 2017.

[3] Boa E. (2004). Wild Edible Fungi: "A Global Overview of their Use and Importance to People". Food and Agriculture Organization of the United Nations. ISBN 92-5-105157-7.

[4] Ejelonu, O.C; Akinmoladun, A.C; Elekofehinti, O.O; Olaleye, M.T. "antioxidant profile of four selected wild edible mushrooms in Nigeria". journal of chemical and pharmaceutical research. 7: 286-295.

[5] M.C. Sandhya, K.N. Prabhu and N. Earanna, "Mushroom Diversity of the Gandhi Krishi Vigyana Kendra (GKVK) Campus", University of Agricultural Sciences, Bangalore, Karnataka (India), International Journal of Current Microbiology and Applied Sciences, 2017.

[6] Paul, Tina Roy, and Nirmalendu Das, "Potentiality of Oyster Mushroom (Pleurotus Spp.) in Medicine- A Review Chandana", Paul C, Roy T, Das N (2017) Potentiality of Oyster Mushroom (Pleurotus Spp.) in Medicine- A Review. Ann Food Process Preserv 2(2): 1014

[7] Ashlea Norton, " Toxicology of the Amanita phalloides (Death Cap) Mushroom Detection of Amatoxins and Phallotoxins by UltraPerformance Liquid Chromatography Coupled with Tandem Mass Spectrometry", A Thesis, Bachelor of Applied Science (Honours) , The University of Canberra December 2014.

[8] Raji A. O And A. O. Alamutu, "Prospects of Computer Vision Automated Sorting Systems in Agricultural Process Operations In Nigeria", Agricultural Engineering International: The CIGR Journal of Scientific Research and Development". Vol. VII. Invited Overview. February 2005

[9] Professor Judy Wajcman, Professor Michael Bittman, Dr Paul Jones, Dr Lynne Johnstone, and Jude Brown, "The Impact of the Mobile Phone on Work/Life Balance", The AMTA/ARC, Preliminary Report June 2007

[10] Jiawei Han, Micheline Kamber, and Jian Pei " Data Mining Concepts and Techniques", Third Edition, 2012 by Elsevier.

[11] Tina R. Patil, Mrs. S. S. Sherekar, "Performance Analysis of Naive Bayes and J48 Classification Algorithm for Data Classification", International Journal Of Computer Science And Applications, Vol. 6, No.2, Apr 2013, ISSN: 0974-1011 (Open Access)

[12] Abd, Dhafar Hamed, et al. "The utilisation of machine learning approaches for medical data classification and personal care system management for sickle cell disease." New Trends in Information \& Communications Technology Applications (NTICT), 2017 Annual Conference on. IEEE, 2017.

[13] Sayali D. Jadhav and H. P. Channe, "Comparative Study of K-NN, Naive Bayes and Decision Tree Classification Techniques", International Journal of Science and Research (IJSR), ISSN (Online): 2319-7064, Volume 5 Issue 1, January 2016.

[14] Joaquín Abellán * and Javier G. Castellano ,Improving the Naive Bayes Classifier via a Quick Variable Selection Method Using Maximum of Entropy", Entropy 2017, 19, 247; doi:10.3390/e19060247.

[15] S.Nagaparameshwara chary, Dr.B.Rama, "A Survey on Comparative Analysis of Decision Tree Algorithms in Data Mining", International Journal of Advanced Scientific Technologies ,Engineering and Management Sciences (IJASTEMS-ISSN: 2454-356X) Volume.3,Special Issue.1,March.2017.

[16] University of California - Irvine. "Mushroom Data Set." Date Accessed: 11/12/2008. http://archive.ics.uci.edu/ml/datasets/Mushroo $\mathrm{m}$.

[17] G. H. Lincoff (Pres.), New York, Alfred A. Knopf, " Mushroom Database ", Mushroom records drawn from The Audubon Society Field Guide to North American Mushrooms (1981). http://archive.ics.uci.edu/ml/machine-learningdatabases/mushroom/agaricus-lepiota.names. 


\section{نظام مساعد لتشخيص نوع الفطر بالاعتماد على التعليم الآّلي باستخدام الأجهزة المحمولة الاعتي علي}

\author{
ظافر حميد عبد المعار \\ كلية المعارف الجامعة ميلة \\ dhafar.dhafar@gmail.com
}

\author{
انتصار شديد المجبلي \\ جامعة تكنولوجيا المعلومات و الاتصالات \\ dr.intisar.almejibli@gmail.com
}

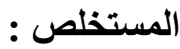

أصبح اختيار الفطر البري من البرية و الغابات لغرض الغذاء أو للمتعة قضية مهمة في السنوات الأخيرة لأن العديد

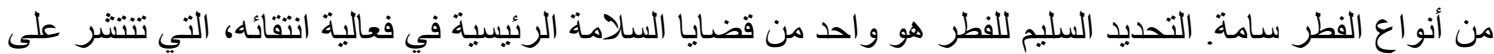
نطاق و اسع، في البلدان. تقترح هذه الورقة نهجا جديدا لدعم تحديد الفطر من خلال استخدام نظام مقترح مع الأجهزة المحمولة. جزء من النظام المقترح هو تطبيق المحمول التي تستخدم بسهولة من قبل المستخدم - ملتقط ثمار الفطر. وبالتالي، يمكن إجر اء عملية تحديد نوع الفطر في أي مكان بناءا على صفات محددة منه. تطبيق تحديد نوع الفطر يعمل على أجهزة المحمول التي تتنتر على نطاق واسع وغير مكلفة بحيث يمكن استغلالها بشكل واسع من قبل المستخدمين. وضعت هذه الورقة نظام مساعدة لتشخيص الفطر (MDAS) الذي يمكن استخدامه على الهاتف المحمول. وتم استخدام اثنين من المصنفات التي هي Naive Bays و Decision Tree لتصنيف أنواع الفطر. النهج المقترح يقوم باختيار الصفات الأكثر فعالية من صفات الفطر المعروفة ، ومن ثم تحديد نوع الفطر . استخدام ميزات محددة في عملية تحديد نوع الفطر حققت نتائج دقيقة جدا. 